\title{
Perbandingan Butiran Kitosan dengan Pengikat Silang Epiklorohidrin (ECH) dan Glutaraldehid (GLA): Karakterisasi dan Kemampuan Adsorpsi Timbal (Pb)
}

\author{
Armeida Dwi Ridhowati Madjid¹, Merpiseldin Nitsae², Akhmad Sabarudin ${ }^{3}$ \\ 1Jurusan Kimia, Fakultas Sains dan Teknologi, Universitas Islam Negeri Maulana Malik Ibrahim, Malang, Indonesia,65145 \\ 2Jurusan Biologi, Fakultas Keguruan dan IImu Pendidikan, Universitas Kristen Artha Wacana, Kupang, Indonesia, 85228 \\ 3Jurusan Kimia, Fakultas Matematika dan IImu Pengetahuan Alam, Universitas Brawijaya, Malang, Indonesia, 65145
}

\section{INFO ARTIKEL}

\section{Riwayat Artikel}

Direvisi 4 November 2018

Diterima 20 Desember 2018

Tersedia online 30 Desember 2018

\footnotetext{
* Email penulis korespondensi: armeida@uin-malang.ac.id
}

\section{ABSTRAK}

Chitosan was an abundantly available source but it has a drawback which unstable in acid or base. So, it must be added with a crosslinker. In this article, we would compare the using of 2 crosslinkers, glutaraldehyde (GLA) and epichlorohydrin (ECH). Chitosan was formed as bead using tripolyphosphate (TPP). Chitosan beads crosslinked with GLA became browny beads and chitosan beads crosslinked with $\mathrm{ECH}$ became pearly white. IR characterization showed peaks in 1640 and $1540 \mathrm{~cm}^{-1}$ represent phosphate contained TPP. There is no significant or unique peak differ GLA chitosan bead from ECH chitosan bead. Adsorption capacity of lead $(\mathrm{Pb})$ in ECH chitosan bead was higher than in GLA chitosan bead. Morphology in SEM characterization exhibited a crinkle GLA chitosan bead then $\mathrm{ECH}$ chitosan bead.

Keywords: Chitosan bead, glutaraldehyde, epichlorohydrin, adsorption

Kitosan merupakan polimer alam dengan ketersediaan yang meruah tetapi memiliki kelemahan yaitu kurang stabil dalam asam maupun basa sehingga diperlukan pengikat silang. Dalam artikel ini akan dibandingkan dengan penggunaan 2 agen pengikatsilang yang dapat mengatasi permasalahan tersebut yaitu epiklorohidrin $(E C H)$ dan glutaraldehid $(G L A)$. Untuk pembuatan butiran kitosan digunakan tripolyphosphate (TPP). Setelah menjadi butiran kitosan diikatsilangkan dengan GLA menjadi butiran kitosan yang berwarna kecoklatan dan diikatsilangkan dengan ECH menjadi butiran kitosan bening. Karakterisasi spektrofotometri Infra Merah menunjukkan puncak pada daerah 1640 dan 1540 $\mathrm{cm}^{-1}$ yang merupakan serapan khas dari tripolyphospate sedangkan tidak nampak perbedaan puncak spektra yang signifikan dari butiran kitosan GLA maupun ECH. Kemampuan adsorpsi butiran logam timbal $(\mathrm{Pb})$ butiran kitosan $\mathrm{ECH}$ lebih tinggi jika dibandingkan dengan butiran kitosan GLA. Morfologi butiran kitosan dianalisis menggunakan Scanning Electron Morphology (SEM) dan menunjukkan bahwa morfologi untuk butiran GLA memiliki morfologi yang lebih berkerut jika dibandingkan dengan butiran $\mathrm{ECH}$.

Kata Kunci: Butiran kitosan, glutaraldehid, epiklorohidrin, adsorpsi 


\section{Pendahuluan}

Kitosan adalah biopolimer hasil deasetilasi dari kitin terdiri atas rantai poly ( $\beta$-1-4)-2-amino-2-deoxy-D-glucopyranose yang mengandung gugus amina $\left(-\mathrm{NH}_{2}\right)$ dan hidroksil $(-\mathrm{OH})$ sebagai pusat afinitasnya [1]. Kinerja adsorpsi dari kitosan dapat ditingkatkan dengan berbagai cara antara lain: grafting (penambahan gugus aktif), crosslink (pengikatsilangan) dan composite (penambahan polimer lain) [2, 3, 4]. Proses pengikatsilangan dapat meningkatkan stabilitas secara kimia yaitu tidak larut dalam asam pekat ( $\mathrm{pH}$ 1) maupun basa [5]. Pada penelitian ini akan membandingkan karakterisasi dan kinerja dari kitosan terikatsilang yaitu epiklorohidrin $(\mathrm{ECH})$ dan glutaraldehid $(\mathrm{GLA})$ karena kedua pengikat silang tersebut memiliki jenis ikatan yang berbeda. GLA membentuk basa Schiff dengan kitosan sedangkan dengan ECH membentuk ikatan tunggal. Kedua pengikat silang tersebut dimungkinkan untuk bereaksi dengan gugus $-\mathrm{NH}_{2}[6]$ tetapi gugus $-\mathrm{NH}_{2}$ tersebut merupakan sisi aktif yang berperan penting dalam proses adsorpsi. Oleh karena itu, gugus $\mathrm{NH}_{2}$ dari kitosan harus diproteksi terlebih dahulu sebelum direaksikan dengan agen pengikat silang. Selain memodifikasi secara kimia dengan penambahan agen pengikat silang, kitosan juga dapat dimodifikasi secara fisika untuk meningkatkan adsorpsinya. Modifikasi secara fisika yang akan dilakukan adalah dengan pembuatan butiran. Dalam bentuk butiran akan mempengaruhi kemampuan kinerja kitosan sebagai adsorben. Dalam bentuk butiran, kitosan akan memiliki kapasitas adsorpsi yang lebih besar dan mempercepat kinetikanya dibandingkan dengan kitosan yang berbentuk flake [7].

Tripolifosfat (TPP) digunakan sebagai protektor gugus $-\mathrm{NH}_{2}$ karena dapat berperan ganda yaitu selain dapat memproteksi gugus $-\mathrm{NH}_{2}$ juga dapat membentuk struktur butiran yang lebih baik jika dibandingkan dengan $\mathrm{NaOH}$ [8]. TPP akan berikatan secara intramolekuler dan intermolekuler sehingga struktur kitosan akan menjadi lebih rigid dan terbentuklah butiran kitosan. Konsentrasi TPP dan lama waktu perendaman dalam TPP akan mempengaruhi kekakuan dari butiran, ukuran pori dan morfologi kitosan butiran yang terbentuk. Selanjutnya, butiran kitosan akan dikeringkan untuk menghilangkan kandungan air sehingga meningkatkan difusi adsorbat ke dalam kitosan. TPP akan dipertahankan dalam butiran karena dimungkinkan untuk meningkatkan kemampuan adsorpsi kitosan karena memiliki gugus negatif $\left(\mathrm{P}_{3} \mathrm{O}_{10^{-}}\right)$ sehingga dimungkinkan untuk membantu proses adsorpsi dalam kitosan [9].

Jumlah logam timbal $(\mathrm{Pb})$ yang teradsorpsi menjadi salah satu ukuran kinerja dari perbandingan kemampuan adsorben yang menggunakan pengikat silang GLA atau ECH. Konsentrasi kadar logam berat akan diukur menggunakan Spektroskopi Serapan Atom (SSA). Dalam penelitian ini akan dilakukan optimasi pembuatan kitosan butiran dengan berbagai variasi konsentrasi pengikat silang (ECH 1\%, 2,5\% dan 5\% dan GLA 2,5\%) dan evaluasi proses optimasi pembuatan dilakukan dengan adsorpsi logam berat secara metode batch. Karakterisasi gugus fungsi butiran kitosan dilakukan dengan menggunakan FTIR dan morfologi permukaan butiran kitosan menggunakan Scanning Electron Morphology (SEM).

\section{Bahan dan Metode}

\subsection{Bahan}

Kitosan dari kulit udang DD 75\% (Himedia), epiklorohidrin (ECH) 99\% (Sigma Aldrich), glutaraldehid (GLA) 25\% (Sigma Aldrich) dan sodium tripolifosfat (TPP) (Sigma Aldrich). Semua bahan yang digunakan adalah analytical grade kecuali sodium TPP 85\% (technical grade).

\subsection{Pembuatan Butiran Kitosan}

Kitosan ditimbang sebanyak 1 gram dilarutkan dalam $100 \mathrm{~mL}$ asam asetat $5 \%(\mathrm{v} / \mathrm{v})$ untuk mendapatkan larutan kitosan $1 \%(\mathrm{~b} / \mathrm{v})$. Kemudian, $5 \mathrm{~mL}$ larutan kitosan dimasukkan ke dalam syringe dan selanjutnya diteteskan pada $10 \mathrm{~mL}$ larutan TPP $1 \%$ (b/v) dan direndam selama 3 jam. Selanjutnya, dilakukan ikat silang dengan direndam dalam ECH $5 \%$ (v/v) dan dioven selama 2 jam pada suhu $50-60^{\circ} \mathrm{C}$. Kitosan yang telah berikatan dengan ECH disaring dan dikeringkan dalam oven pada suhu $105^{\circ} \mathrm{C}$. Kemudian dilakukan hal yang sama dengan memvariasi konsentrasi larutan ECH dengan konsentrasi $1 \%$ dan 2,5\% dan larutan pengikat silang diganti menjadi GLA (2,5\%). Untuk crosslinker GLA, proses pengikatan silang tanpa dilakukan pemanasan hanya dilakukan dengan perendaman selama 24 jam. Uji optimasi dengan cara uji ekstraksi sebanyak $25 \mathrm{~mL}$ larutan limbah logam laboratorium 25 ppm dengan metode batch selama 1,5 jam, dikocok dengan menggunakan shaker dengan kecepatan $100 \mathrm{rpm}$ dan pH tidak dikondisikan. Setelah adsorpsi, larutan diambil sebanyak $5 \mathrm{~mL}$ dan diukur langsung logam $\mathrm{Pb}$ menggunakan $\mathrm{SSA}$. Untuk masing-masing perlakuan dilakukan perulangan sebanyak 6 kali.

\subsection{Jumlah Logam Berat yang Teradsorpsi}

Untuk setiap tahapan optimasi maka akan dihitung jumlah logam berat yang teradsorpsi $(Q)$ dengan persamaan (1).

$$
Q=\frac{\left(C_{0}-C_{e}\right) \times v}{m}
$$


Dimana $C_{0}$ adalah konsentrasi awal logam, $C_{e}$ adalah konsentrasi logam setelah proses ekstraksi, $V$ adalah volume logam dan $\mathrm{m}$ adalah massa adsorben. Besar sampel penelitian dihitung berdasarkan rancangan acak lengkap dimana secara sederhana dirumuskan sebagaimana Persamaan (2).

$$
(\mathrm{t}-1)(\mathrm{r}-1)>15
$$

Dimana t adalah banyaknya kelompok perlakuan dan $r$ adalah jumlah replikasi. Selanjutnya, untuk mengetahui pengaruh dari perlakuan terhadap besarnya konsentrasi logam yang terserap maka akan diuji dengan uji statistik One Way Anova pada masing-masing variasi perlakuan serta Uji BNT.

\subsection{Karakterisasi Menggunakan FTIR dan SEM}

Karakterisasi kitosan makropori dengan menggunakan spektroskopi inframerah (FTIR) dilakukan untuk mengetahui perubahan gugus fungsi pada tiap-tiap proses pembuatan butiran kitosan. Butiran kitosan (setelah modifikasi) dan kitosan tanpa dimodifikasi masing-masing dicampurkan dengan $\mathrm{KBr}$ dan ditumbuk hingga halus, dan kemudian diletakkan pada sebuah cetakan untuk dibuat pelet. Karakterisasi terhadap kepingan sampel dilakukan dengan FTIR Varian. Analisis SEM dilakukan pada butiran kitosan GLA dan ECH dengan diawali dengan pelapisan menggunakan emas dan diukur pada perbesaran tertentu.

\section{Hasil dan Pembahasan}

\subsection{Pembuatan Butiran Kitosan}

Pembuatan butiran kitosan diawali beberapa tahapan pembuatan yaitu pertama kitosan yang telah dilarutkan dalam asam asetat dimasukkan ke dalam syringe, kemudian diteteskan ke dalam larutan TPP sehingga terbentuklah butiran. Selanjutnya butiran yang didapatkan, disaring dan ditambahkan dalam larutan $\mathrm{ECH}(1 \%, 2,5 \%$ dan $5 \%)$ untuk proses ikatan silang dan dioven selama 2 jam pada suhu $50-60^{\circ} \mathrm{C}$. Untuk pengikat silang $\mathrm{GLA}$, setelah terbentuk butiran maka langsung dimasukkan ke dalam larutan GLA 2,5\% dan direndam selama 24 jam dan terdapat perubahan beads menjadi kekuningan dan lama kelamaan menjadi coklat. Setelah dilakukan proses pengikatan silang baik dengan ECH maupun GLA, butiran kitosan disaring dan dicuci menggunakan akuades dan dikeringkan pada suhu kamar. Proses pembuatan ini dapat dilihat pada Gambar 1.
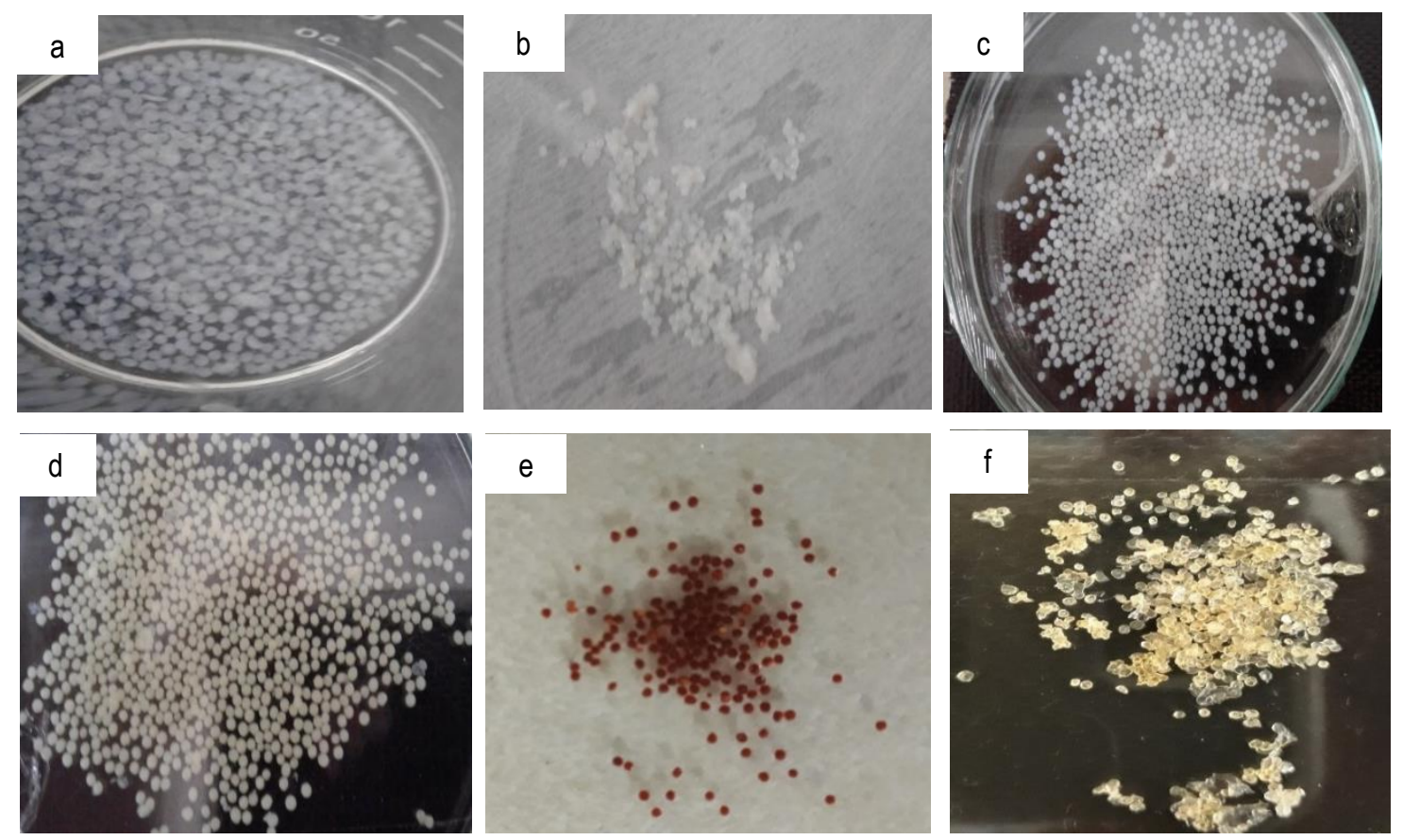

Gambar 1. Proses pembuatan butiran kitosan terikatsilang. (a) Larutan kitosan menjadi butiran dalam larutan TPP, (b) Butiran kitosan setelah disaring setelah perendaman dalam TPP selama 3 jam, (c) Butiran kitosan dalam ECH, (d) Butiran kitosan dalam GLA, (e) Butiran kitosan dengan pengikat silang GLA setelah dikeringkan, dan (f) Butiran kitosan dengan pengikat silang ECH setelah dikeringkan.

Kitosan sebagai adsorben perlu dimodifikasi sebelum digunakan yaitu dengan penambahan crosslinker seperti GLA ataupun ECH agar lebih stabil dalam asam. Selain itu, kitosan secara fisik akan dibuat dalam bentuk butiran dengan mereaksikan dengan TPP. Kitosan perlu dilarutkan terlebih dahulu dengan asam asetat $5 \%$ kemudian dibuat menjadi 
butiran dengan meneteskannya pada larutan TPP 1\% selanjutnya dibiarkan selama 3 jam. Reaksi yang terjadi antara kitosan dengan TPP dapat dilihat dalam Gambar 2. Melalui reaksi tersebut diketahui bahwa reaksi antara kitosan dengan TPP terjadi secara fisika dimana tidak terjadi ikatan kimia hanya berupa ikatan elektrostatik. Namun, dapat saat larutan kitosan diteteskan ke dalam larutan TPP maka akan langsung terbentuk butiran-butiran seperti yang telah ditunjukkan dalam Gambar 1 (a) dan (b). Konsentrasi TPP dan lama perendaman dalam kitosan akan menentukan kekerasan dari butiran kitosan dan saat proses pengeringan maka butiran dapat dipertahankan. Pada penelitian ini dipilih konsentrasi TPP $1 \%$ dengan lama perendaman 3 jam dengan pertimbangan akan mempermudah proses adsorpsi sebab jika terlalu lama dengan konsentrasi TPP terlalu tinggi maka butiran kitosan akan kaku sehingga mempersulit difusi logam ke dalam logam. Butiran kitosan yang telah terbentuk selanjutnya akan direaksikan dengan 2 agen pengikat silang yang berbeda. Agen pengikat silang yang digunakan adalah GLA. Proses pengikatan silang tidak memerlukan pemanasan hanya direndam selama 24 jam. Setelah 24 jam, butiran kitosan menjadi lebih kecoklatan (Gambar 1 e). Reaksi yang terjadi antara butiran kitosan dengan GLA ditunjukkan pada Gambar 3.

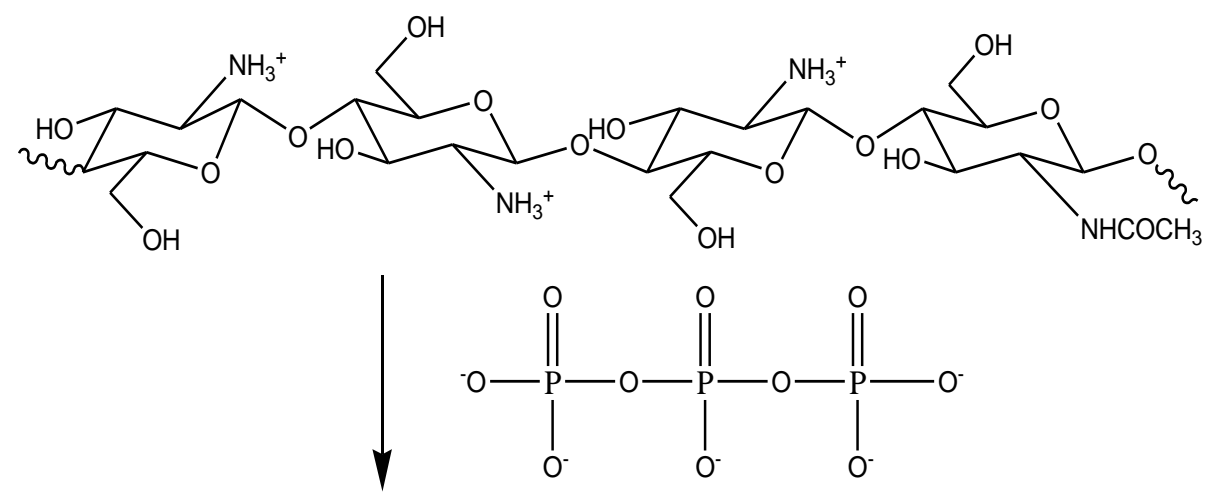

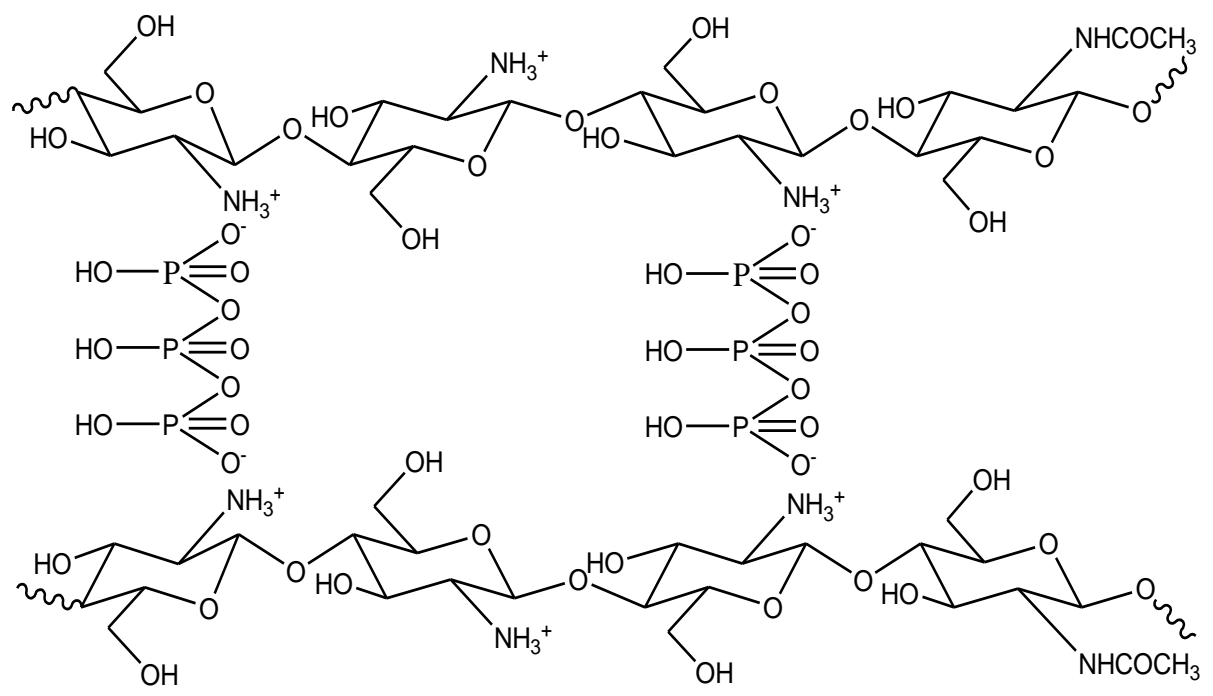

Gambar 2. Reaksi kitosan dengan tripolifosfat (TPP).

Berbeda dengan GLA yang terikat pada gugus amina $\left(-\mathrm{NH}_{2}\right), \mathrm{ECH}$ berikatan dengan gugus hidroksil $(-\mathrm{OH})$. Selain itu, waktu untuk pengikatan silang dilakukan dengan pemanasan pada suhu $50-60^{\circ} \mathrm{C}$ selama 2 jam. Reaksi antara kitosan dengan ECH ditunjukkan pada Gambar 4. Jika dilihat dari Gambar 4 tersebut maka menunjukkan bahwa setelah kering (Gambar 6 e dan f), butiran dengan pengikat silang GLA berbentuk bulat kecoklatan sedangkan untuk kitosan dengan pengikat silang ECH butiran yang bening. Jika melihat dari proses pengikat silang yang lebih lama pada GLA (24 jam) dibandingkan dengan ECH mempengaruhi bentuk setelah kering. Selain itu, jika semakin banyak yang bereaksi dengan gugus amina dari kitosan maka butiran kitosan yang terbentuk semakin keras/kaku. Setelah proses pengeringan, air yang terperangkap dalam butiran kitosan akan hilang sehingga jika proses pengikatan silang tidak maksimal maka bentuk butiran tidak dapat dipertahankandan berubah menjadi menjadi flake. Namun, hal tersebut tidak terjadi baik pada butiran kitosan ECH maupun GLA. 

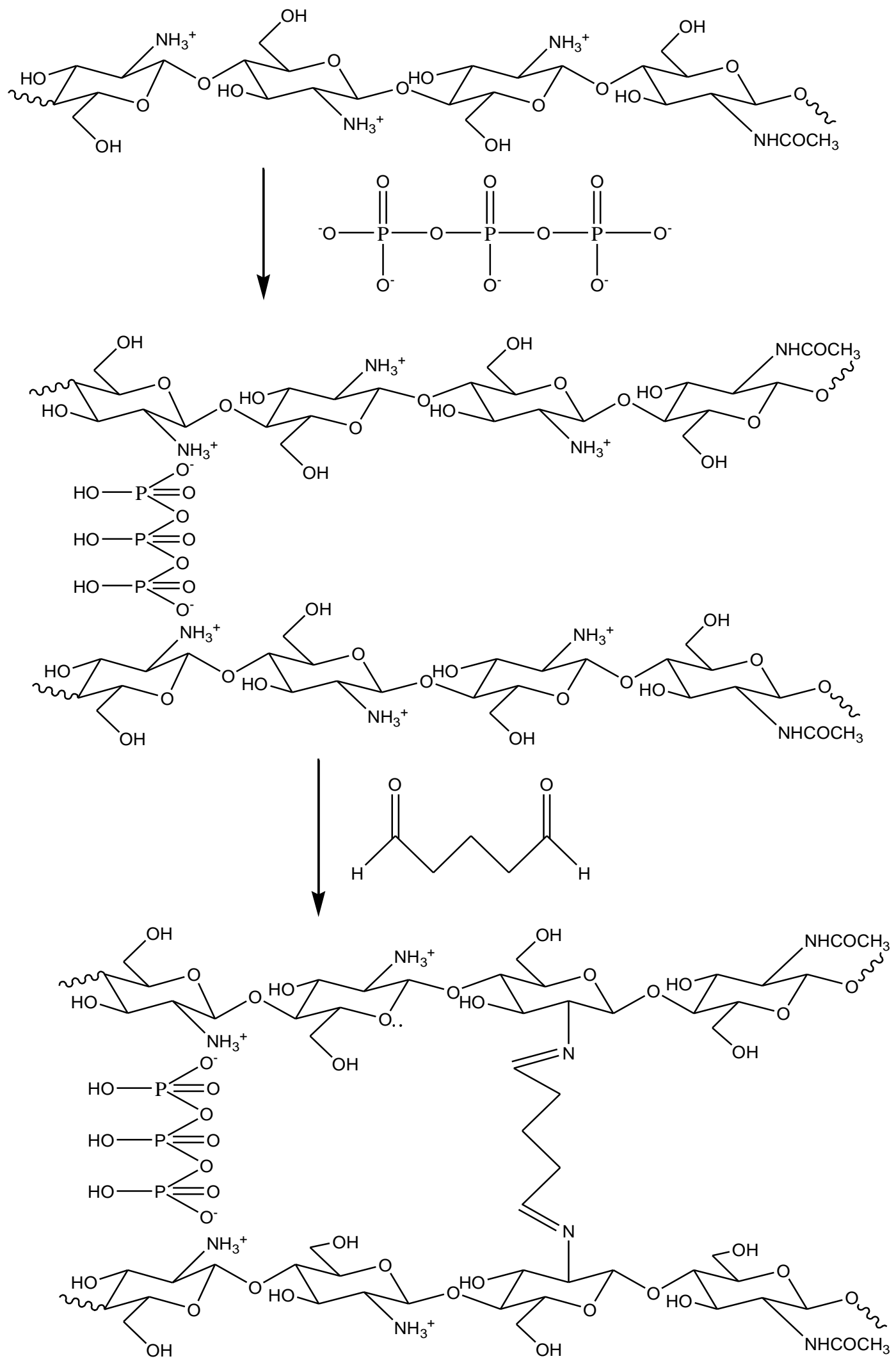

Gambar 3. Reaksi butiran kitosan dengan glutaraldehid (GLA). 


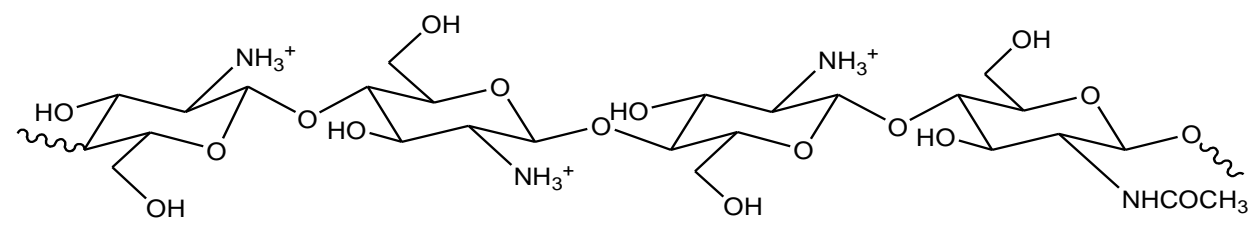<smiles>[13CH3]I</smiles>

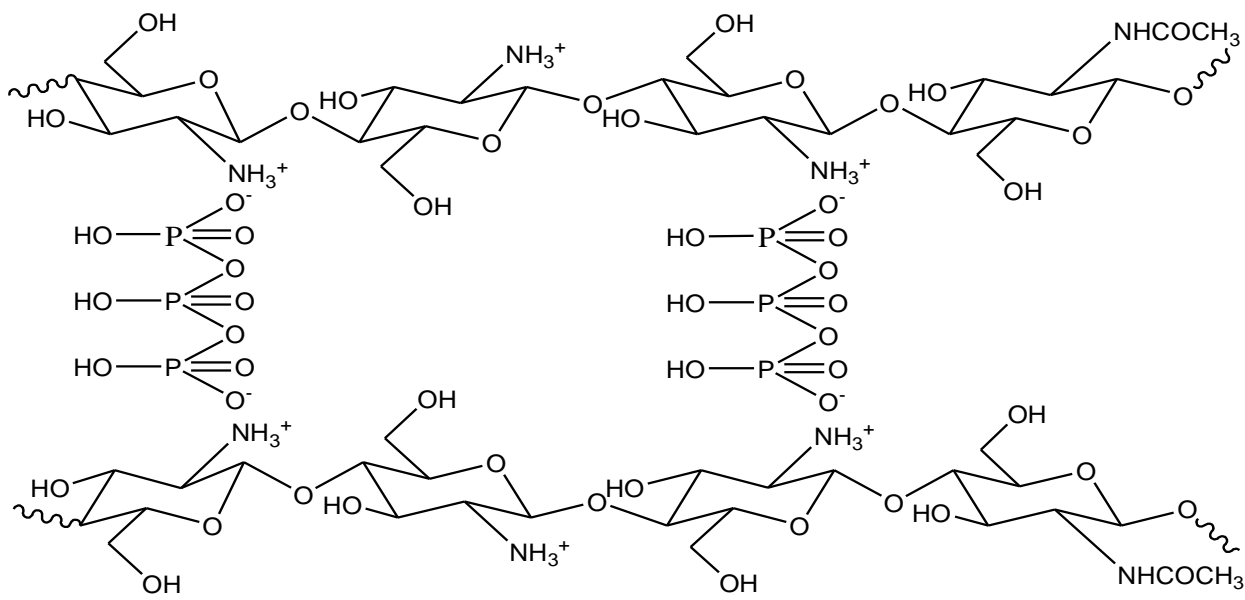
${ }_{\mathrm{O}}^{\mathrm{H}} \mathrm{C}-\mathrm{CH}-\mathrm{CH}_{2} \mathrm{Cl}$ : pemanasan pada suhu $50-60^{\circ} \mathrm{C}$

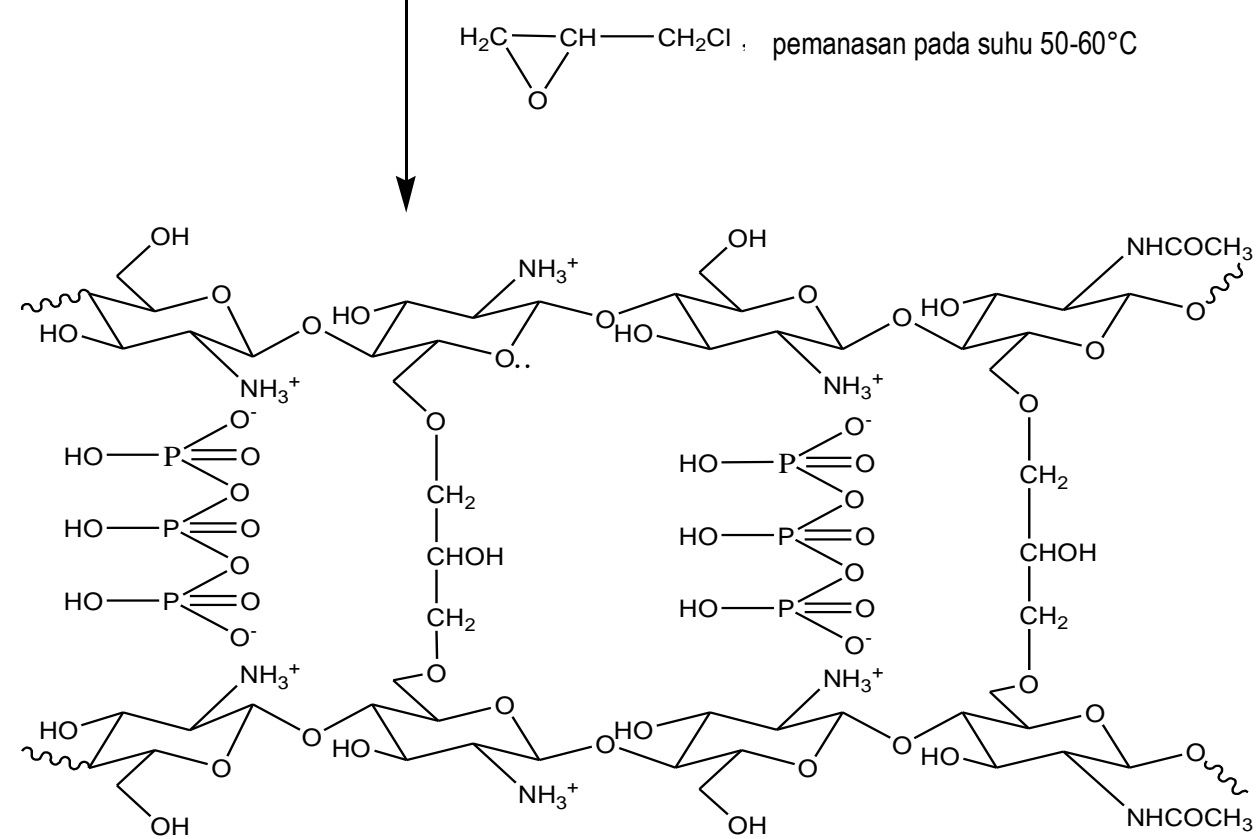

Gambar 4. Reaksi butiran kitosan dengan epiklorohidrin (ECH).

\subsection{Kemampuan Adsorpsi Butiran Kitosan}

Proses adsorpsi logam $\mathrm{Pb}$ dilakukan dengan mengujicobakan butiran kitosan yang telah dibuat pada larutan logam buatan (larutan $\mathrm{Pb}\left(\mathrm{NO}_{3}\right)$ dengan metode batch yaitu dengan menambahkan sejumah butiran kitosan ke dalam larutan $\mathrm{PbNO}_{3}$ kemudian dikocok menggunakan shaker dengan kecepatan $100 \mathrm{rpm}$. Dengan membandingkan konsentrasi $\mathrm{Pb}$ sebelum dan sesudah proses adsorpsi maka metode adsorpsi yang memiliki selisih terbesar atau jumlah logam yang terserap (Q). Telah dibuat butiran kitosan dengan GLA (2,5\%) dan ECH (1\%, 2,5\% dan 5\%) dan telah dilakukan proses adsorpsi sehingga didapatkan data yang seperti pada Gambar $\mathbf{5}$. 


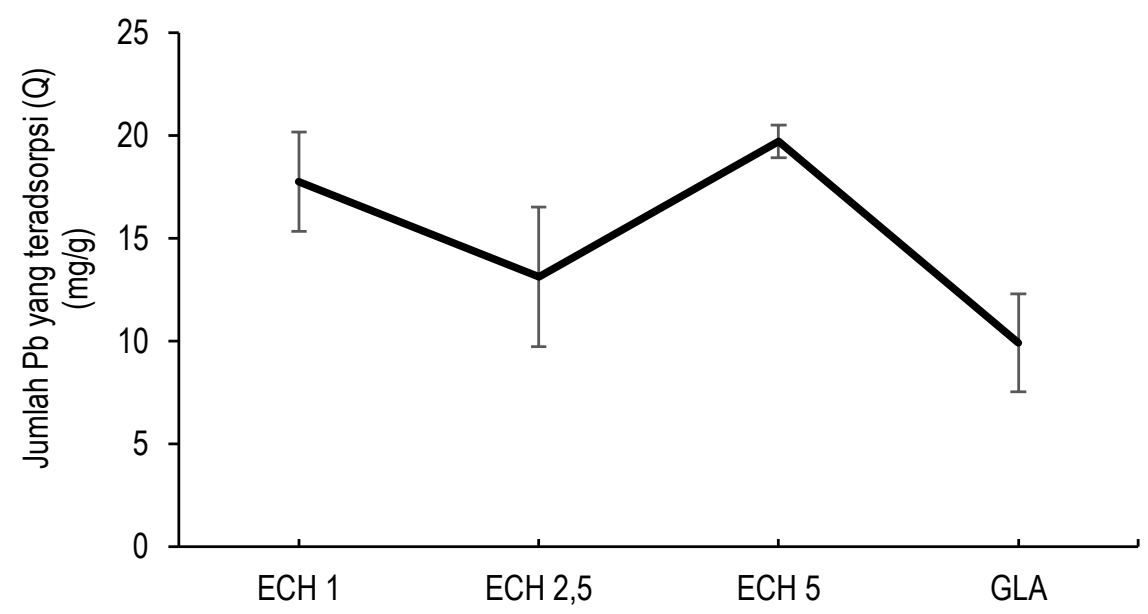

Gambar 5. Pengaruh agen pengikat silang dan konsentrasinya terhadap kapasitas adsorpsi butiran kitosan terhadap logam timbal $(\mathrm{Pb})$.

Gambar 5 menunjukkan pengaruh jumlah $\mathrm{Pb}$ yang teradsorpsi pada butiran kitosan dengan agen pengikat silang ECH maupun GLA. Angka yang ditunjukkan setelah ECH mewakili konsentrasi ECH yang digunakan dalam proses pembuatan butiran kitosan. Metode penambahan ECH ke dalam kitosan dapat dilakukan dengan berbagai cara yaitu dengan penambahan ECH pekat ke dalam kitosan seperti yang dilakukan oleh Chen dkk. [10] dan Laus dkk. [9] atau dilarutkan dalam larutan basa $(\mathrm{NaOH})$ seperti oleh Obeid dkk. [3]. Namun, kedua cara tersebut tidak dapat dilakukan karena ingin menjaga agar TPP tetap terikat pada gugus $-\mathrm{NH}_{2}$ kitosan. Mengingat kelarutan $\mathrm{ECH}$ yang rendah dalam air $(6,6 \%$ pada suhu $20^{\circ} \mathrm{C}$ ) maka variasi konsentrasi $\mathrm{ECH}$ yang dapat digunakan dalam pembuatan butiran kitosan terbatas pada 1 , 2,5 dan $5 \%$. Untuk GLA, konsentrasi yang digunakan adalah $2,5 \%$.

Pada Gambar 5 menunjukkan bahwa dengan menggunakan agen pengikat silang ECH didapatkan jumlah logam $\mathrm{Pb}$ yang terserap lebih banyak dibandingkan dengan GLA dan yang paling tertinggi adalah butiran kitosan dengan agen pengikat silang $\mathrm{ECH} 5 \%$. Hal tersebut ditinjau dari besarnya jumlah $\mathrm{Pb}$ yan teradsorpsi dan jika dilihat dari simpangan deviasinya maka didapatkan yang paling terkecil dari 6 kali ulangan pengukuran walaupun jika dilihat dari uji BNT (Fisher Method) ECH 5\% dan 1\% tidak berbeda nyata dengan derajat kesalahan 5\%. Dalam proses transformasi atau pembuatan dibutuhkan konsistensi perlakuan serta kondisi. Oleh karena itu, besarnya simpangan baku sangatlah penting.

Selain itu, menurut uji One Way ANOVA menunjukkan bahwa memang ada pengaruh dari agen pengikat silang dari pembuatan butiran kitosan terhadap jumlah logam $\mathrm{Pb}$ yang teradsorpsi $(Q)$ ( $F$ hitung $=20,02>F$ tabel $(13,75)$ ). Maka dari proses optimasi ini dapat disimpulkan bahwa kekakuan butiran kitosan yang muncul diakibatkan dari reaksi antara gugus amina dengan agen pengikat silang harus dikontrol dengan baik sehingga perlu dicoba untuk mengurangi waktu pengikatan silang pada GLA menjadi kurang dari 24 jam. Dengan demikian, maka kemampuan adsorpsi dari butiran kitosan dengan pengikat silang $\mathrm{ECH} 5 \%$ lebih baik dibandingkan komposisi lainnya sehingga dapat diteruskan untuk dilakukan optimasi lebih lanjut seperti pengaruh $\mathrm{pH}$, pengaruh waktu kontak, pengaruh konsentrasi logam, proses desorpsi, dan aplikasi langsung pada limbah laboratorium.

\subsection{Karakterisasi Butiran Kitosan dengan FTIR dan SEM}

Berdasarkan reaksi yang telah ditunjukkan pada Gambar 2, 3, dan 4 maka terjadi penambahan gugus fungsi yang nampak juga dari spektra IR (Gambar 6). Adanya serapan pada daerah sekitar 1640 dan $1540 \mathrm{~cm}^{-1}$ menunjukkan keberadaan dari TPP. Namun, secara umum tidak terdapat perbedaan dari butiran kitosan dengan pengikat silang ECH dan GLA. Pembentukan gugus imina pada butiran kitosan dengan pengikat silang GLA muncul di daerah yang sama dengan gugus $\mathrm{P}=\mathrm{O}$ dari TPP dan sedangkan butiran kitosan dengan pengikat silang $\mathrm{ECH}$ tidak terdapat gugus fungsi yang spesifik yang berbeda dari kitosan tetapi secara nyata telah terdapat perbedaan dari bentukan kitosan awal yang menjadi butiran serta munculnya perubahan warna butian pada butiran kitosan GLA menunjukkan proses pengikatan silang berjalan seperti yang diharapkan. 


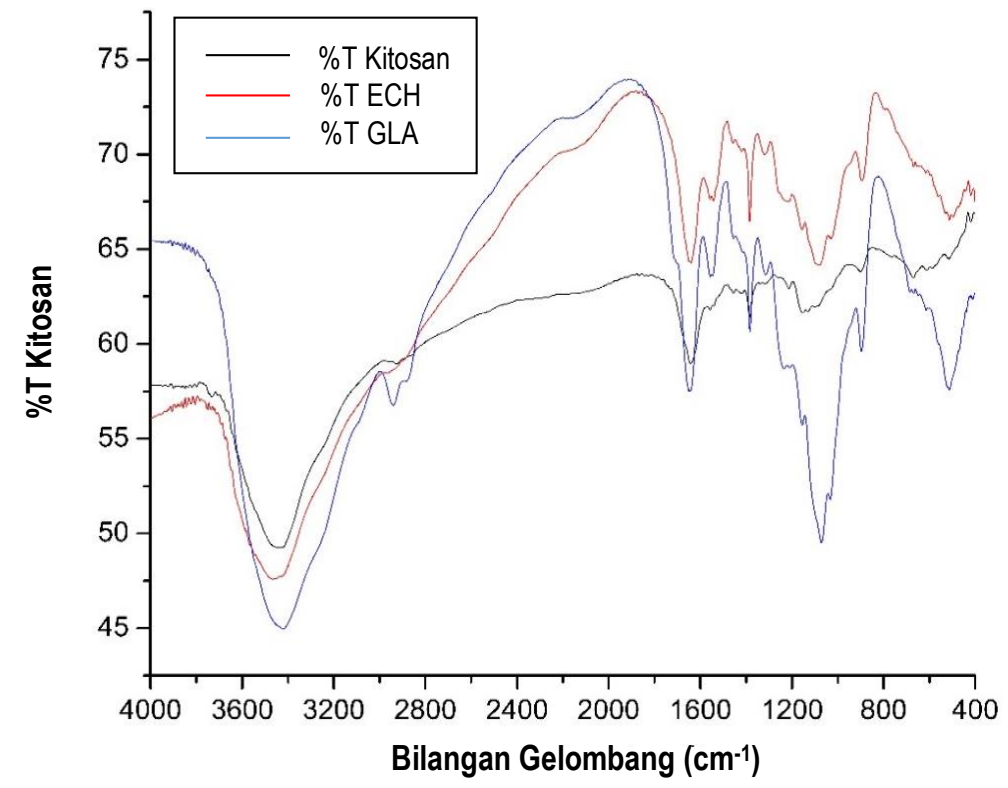

Gambar 6. Spektra IR dari kitosan dan butiran kitosan

Butiran kitosan dilakukan proses analisis menggunakan SEM agar diketahui morfologi permukaan dan ukuran butiran kitosan yang telah dibuat. Hasil analisis menggunakan SEM dapat terlihat dari Gambar 7. Pada gambar tersebut menunjukkan bahwa permukaan butiran kitosan GLA lebih berkerut jika dibandingkan dengan butiran kitosan ECH. Namun, jika melihat kinerjanya butiran ECH memiliki kemampuan adsorpsi yang lebih baik sehingga dimungkinkan dengan butiran kitosan GLA yang lebih kaku dan morfologi yang berkerut diakibatkan dari proses pengikatan silang glutaraldehid pada permukaan kitosan. Hal tersebut menjadi faktor kapasitas adsorpsi dari butiran kitosan GLA lebih rendah daripada ECH.
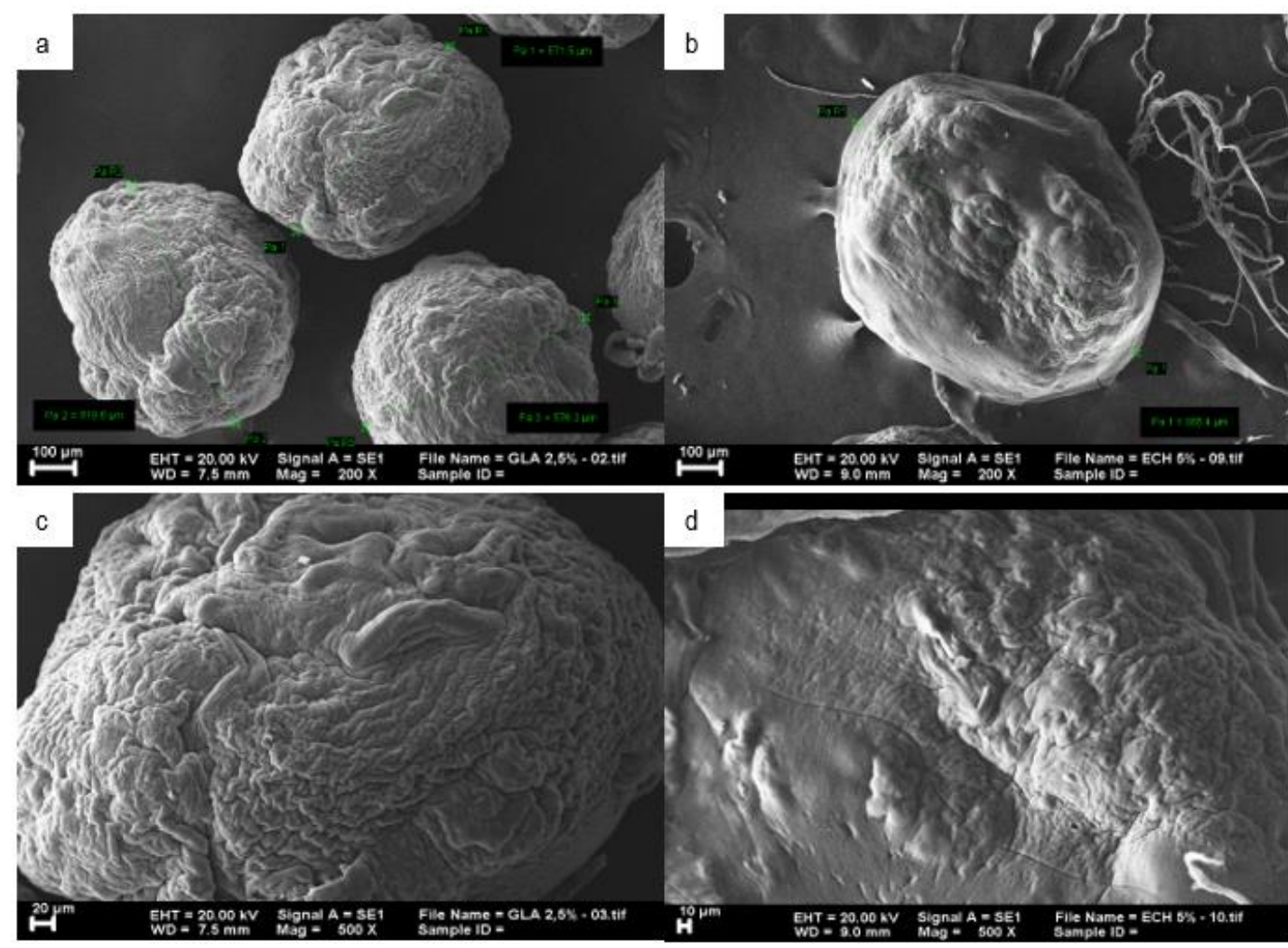

Gambar 7. Analisis SEM butiran kitosan. Butiran kitosan GLA perbesaran 200x (a), 500x (c) butiran kitosan ECH 200x (b) dan $500 x(d)$. 


\section{Kesimpulan}

Terdapat perbedaan pada butiran kitosan yang dibuat menggunakan agen pengikat silang ECH dan GLA dimana butiran kitosan GLA menjadi berwarna kecoklatan dan ECH lebih bening. Spektra IR tidak menunjukkan perbedaan yang signifikan untuk butiran kitosan dengan agen pengikat silang ECH maupun GLA karena spektra serapan tidak dapat dipisahkan dari yang berasal dari kitosan walaupun serapan khas dari TPP muncul pada daerah sekitar 1640 dan 1540 $\mathrm{cm}^{-1}$. Butiran kitosan ECH 5\% memiliki tingkat adsorpsi logam Pb lebih tinggi jika dibandingkan dengan butiran kitosan ECH 1\%, ECH 2,5\% serta GLA. Hasil SEM menunjukkan bahwa butiran kitosan GLA lebih berkerut jika dibandingkan dengan butiran kitosan ECH. Namun, jika melihat kinerjanya butiran ECH memiliki kemampuan adsorpsi yang lebih baik sehingga dimungkinkan dengan butiran kitosan GLA yang lebih kaku dan morfologi yang berkerut diakibatkan dari proses pengikatan silang GLA pada permukaan kitosan sehingga perlu dicoba untuk mengurangi waktu pengikatan silang pada GLA menjadi kurang dari 24 jam. Selain itu, untuk ECH perlu ditambahkan konsentrasi TPP atau lama perendaman dalam TPP agar butiran kitosan tetap terjaga dan diteruskan untuk dioptimasi lebih lanjut kinerja butiran kitosan ECH $5 \%$ seperti pengaruh $\mathrm{pH}$, pengaruh waktu kontak, pengaruh konsentrasi logam, proses desorpsi, dan aplikasi langsung pada limbah laboratorium.

\section{Ucapan Terima Kasih}

Penulis mengucapkan terima kasih kepada penyelenggara Penelitian Kompetitif Tahun Anggaran 2017 Peningkatan Akses, Mutu, Kesejahteraan dan Subsidi Pendidikan Tinggi Islam, Lembaga Penelitian dan Pengabdian Masyarakat (LP2M) UIN Maulana Malik Ibrahim Malang atas dana penelitian yang diberikan.

\section{Daftar Pustaka}

[1]. W. S. W. Ngah \& S. Fatinathan, "Adsorption Characterization of $\mathrm{Pb}(\mathrm{II})$ and $\mathrm{Cu}(\mathrm{II})$ lons onto Chitosan-Tripolyphosphate Beads: Kinetic, Equilibrium and Thermodynamic Studies," Journal of Environmental Management, vol. 91, no. 4, pp. 958-969, 2010.

[2]. G. Crini \& P-M. Badot, "Application of Chitosan, A Natural Aminopolysaccharide, for Dye Removal from Aqueous Solutions by Adsorption Processes using Batch Studies: A Review of Recent Literature," Progress in Polymer Science, vol. 33, no. 4, pp. 399-447, 2008.

[3]. L. Obeid, A. Bée, D. Talbot, S. B. Jaafar, V. Dupuis, S. Abramson, V. Cabuil, \& M. Welschbillig, "Chitosan/Maghemite Composite: A Magsorbent for the Adsorption of Methyl Orange," Journal of Colloid and Interface Science, vol. 410, pp. 52-58, 2013.

[4]. C. Chen, L. Liu, T. Huang, Q. Wang, \& Y. Fang, "Bubble Template Fabrication of Chitosan/Poly(Vinyl Alcohol) Sponges for Wound Dressing Applications," International Journal of Biological Macromolecules, vol. 62 pp. 188-193, 2013.

[5]. A-H. Chen \& Y-Y. Huang, "Adsorption of Remazol Black 5 from Aqueous Solution by the Templated CrosslinkedChitosans," Journal of Hazardous Materials, vol. 177, no. 1-3, pp. 668-675, 2010.

[6]. F-C. Wu, R-L. Tseng, \& R-S. Juang, "A Review and Experimental Verification of Using Chitosan and Its Derivatives as Adsorbents for Selected Heavy Metals," Journal of Environmental Management, vol. 91, no. 4, pp.798-806, 2010.

[7]. F-C. Wu, R-L. Tseng, \& R-S. Juang, "Comparative Adsorption of Metal and Dye on Flake- and Bead-Types of Chitosans Prepared from Fishery Wastes," Journal of Hazardous Materials, vol. 73, no. 1, pp. 63-75, 2000.

[8]. R. Laus, T. G. Costa, B. Szpoganicz, \& V. T. Fávere, "Adsorption and Desorption of $\mathrm{Cu}(\mathrm{II}), \mathrm{Cd}(\mathrm{II})$ and $\mathrm{Pb}(\mathrm{II})$ lons using Chitosan Crosslinked with Epichlorohidrin-Triphosphate as the Adsorbent," Journal of Hazardous Materials, vol. 183, no. 1-3, pp. 233-241, 2010.

[9]. A. D. R. Madjid, M. Nitsae, Atikah, \& A. Sabarudin, "Pengaruh Penambahan Tripolyfosfat pada Kitosan Beads untuk Adsorpsi Methyl Orange," Jurnal MIPA, vol. 38, no. 2, pp. 144-149, 2015.

[10]. A-H. Chen, S-C. Liu, C-Y. Chen, \& C-Y. Chen, "Comparative Adsorption of $\mathrm{Cu}(\mathrm{II}), \mathrm{Zn}(\mathrm{II})$, and $\mathrm{Pb}(\mathrm{II})$ lons in Aqueous Solution on the Crosslinked Chitosan with Epichlorohydrin, Journal of Hazardaous Materials, vol. 154, no. 1-3, pp. 184-191, 2008. 